\title{
SOCIABILIDADES CATÓLICAS POST-CONCILIARES. EL CASO DE LA CONSTELACIÓN TERCERMUNDISTA EN LA ARGENTINA (1966-1976)
}

\section{POST-COUNCIL CATHOLIC SOCIABILITY. THE CASE OF THE \\ THIRD-WORLD MOVEMENT IN ARGENTINA (1966-1976)}

DOI: 10.5533/1984-2503-20102307

\section{Claudia Touris}

\section{RESUMO}

O objetivo central deste artigo é analisar a relação das sociabilidades católicas renovadas através do Concílio Vaticano II e o desenvolvimento da corrente terceiromundista na Argentina. Destacamos quais eram e em que situação se encontravam os principais âmbitos da sociabilidade católica no começo dos anos 1960 e como influenciaram a conformação de redes onde se deu o diálogo entre indivíduos e grupos heterogêneos com forte presença jovem. Enfocamos, sobretudo, o caso do clero paroquial, ou seja, do grupo de sacerdotes terceiro-mundistas que desenvolveram seu trabalho eclesiásticos nas cidades emergentes radicadas em bairros marginais da cidade de Buenos Aires que constituíram o núcleo da constelação terceiro-mundista entre 1966 e 1976.

Palavras-chaves: sociabilidades católicas; juventude; sacerdotes terceiro-mundistas; Argentina.

\section{RESUMEN}

El objetivo central de este artículo es analizar la relación de las sociabilidads católicas renovadas tras el Concilio Vaticano II y el desarrollo de la corriente tercermundista en la Argentina. Mostraremos cuáles eran y en qué situación se encontraban los principales ámbitos de sociabilidad católica a comienzos de los años '60 y cómo influyeron en la conformación de redes donde se dio el diálogo entre individuos y grupos heterogéneos 
con fuerte presencia juvenil. Focalizaremos, sobre todo, en el caso de los curas villeros, es decir del grupo de sacerdotes tercermundistas que desarrollaron su trabajo eclesial en las villas de emergencia radicadas en barrios marginales de la ciudad de Buenos Aires y que constituyeron el núcleo de la constelación tercermundista entre 1966 y 1976.

Palabras-claves: sociabilidads católicas; juventud; sacerdotes tercermundistas.

\section{ABSTRACT}

The main objective of this article is to analyze the relation between catholic sociability, renewed through the Second Vatican Council, and the development of third-world movement in Argentina. The spheres of catholic sociability in the beginning of the sixties as they were are highlighted, as well as their influence on settling the dialogue between people and heterogenic groups with strong youth presence. The case of the parochial clergy, a group of third-world ministers who developed their ecclesiastic work in emerging cities settled in the outskirting neighborhoods of Buenos Aires, constituting the center of the third-world movement between 1966 and 1976, is focused.

Key-words: catholic sociability; youth; third-world ministers.

\section{RÉSUMÉ}

Le principal objectif de cet article est d'analyser le rapport entre les sociabilités catholiques rénovées par le Concile Vatican II et le développement du courant tiersmondiste en Argentine. Nous montrerons quelles étaient et dans quelle situation se trouvaient les principales sphères de sociabilité catholique dans les années 1960. Nous verrons aussi comment elles influencèrent la constitution de réseaux au sein desquels eut lieu un dialogue entre individus et groupes hétérogènes avec une forte présence de la jeunesse. Nous nous intéresserons principalement au cas du clergé paroissial, un groupe de sacerdoces tiers-mondistes qui développa ses activités ecclésiastiques dans les villes émergentes situées dans la banlieue défavorisée de Buenos-Aires et constituera le noyau du courant tiers-mondiste entre 1966 et 1976.

Mots-clés : sociabilités catholiques ; jeunesse; sacerdoces tiers-mondistes. 


\section{Introducción}

Entre fines de la década del '60 y mediados de los años '70 la Argentina vivió una fase de contestación social y de radicalización política sin precedentes derivada del cruce del clima de "revuelta cultural" de alcance mundial, así como, de fenómenos exclusivamente locales asociados a la proscripción del peronismo y al ensayo autoritario de la Revolución Argentina (1966-1973).

Una de las novedades que se evidenció en este proceso, que eclosionó en mayo de 1969, en la rebelión obrero-estudiantil que estalló en la ciudad de Córdoba, (popularmente conocida como "Cordobazo") era que dentro de los grupos que se exhibían como actores protagónicos de un movimiento que se autodefinía socialista y revolucionario, no sólo estaba involucrada la clase obrera de orientación peronista. También lo integraban sectores de clase media preferentemente universitaria vinculados a agrupaciones políticas pertenecientes a una izquierda renovada ("Nueva Izquierda") y otros grupos de formación católica inspirados en el clima de aggiornamento que había traído a la Iglesia católica el Concilio Vaticano II (CVII): 19621965. Entre estos últimos, se destacaron los sacerdotes tercermundistas quienes desde fines de 1967, conformaron una agrupación denominada Movimiento de Sacerdotes para el Tercer Mundo (MSTM), inspirada en el Mensaje de los 18 Obispos del Tercer Mundo promovido por el Obispo de Olinda y Recife, Dom Hélder Cámara.

Dicho colectivo sacerdotal, que tuvo sus equivalentes latinoamericanos en los grupos ONIS de Perú, Golconda, de Colombia y Sacerdotes para el Pueblo de México, se caracterizó, sin embargo, por ser una variante local de lo que más tarde se denominaría Teología de la Liberación, ya que su impronta teológica era más populista y culturalista que marxista. Además, se caracterizó por la adhesión al peronismo de un sector mayoritario de sus integrantes, lo que también le otorgaría una especificidad diferencial respecto de aquellos otros movimientos.

El MSTM, representó a casi el 9\% del clero argentino de aquellos años, (alrededor de 450 sacerdotes), predominando los diocesanos de edades entre 30 y 40 años. Aunque se trató de un movimiento exclusivamente clerical, el influjo de dichos clérigos trascendió los ámbitos intelectuales de formación católica, o de las parroquias, y su presencia fue muy importante en ambientes populares como barrios, villas de 
emergencias ${ }^{1}$, fábricas y sindicatos, al mismo tiempo que actuaban como asesores de los estudiantes secundarios y universitarios que pertenecían a las ramas especializadas de la Acción Católica: Juventud de Estudiantes Católicos (JEC) y Juventud Universitaria Católica (JUC). Se desempeñaron, también, como coordinadores de grupos de reflexión y prácticas pastorales existentes en diversos ámbitos donde participaban laicos y religiosas.

El catolicismo tercermundista argentino, aunque adhirió a la línea liberacionista ${ }^{2}$, fue portador de algunos rasgos específicos que le dieron cierta singularidad dentro de dicha corriente. EI MSTM fue el grupo que logró condensar con mayor fuerza esta concepción. Su adhesión inicial a un socialismo definido como humanitario, cristiano y latinoamericano, se fue confundiendo cada vez más con una opción que políticamente iba a expresarse en el apoyo al peronismo, en la coyuntura 1972-1976.

Sin embargo, queremos subrayar que cualquier intento de explicar los alcances de esta tendencia eclesial en la Argentina no puede dejar de reconocer que el tercermundismo católico fue una constelación bastante más extendida hacia una red donde además de los clérigos participaban grupos de cristianos radicalizados y nucleados en torno a la Revista Cristianismo y Revolución: C y R: (1966-1971) y que entendían como legítima la lucha armada. Pero dentro de esta constelación, también se ubicaron y actuaron las religiosas que se insertaron en villas miseria, barrios populares, movimientos campesinos y que estaban imbuidas del mismo imaginario ${ }^{3}$ liberacionista

\footnotetext{
${ }^{1}$ Asentamiento poblacional de extrema precariedad material situado en las grandes ciudades. En el caso argentino las "villas miseria" o de emergencia comenzaron a desarrollarse desde la década del '30 y estuvieron asociadas al fenómeno de la industrialización y a las migraciones internas. Son comparables a las favelas y los cantegriles para los casos de Brasil y Uruguay respectivamente.

${ }^{2}$ Por las razones anteriormente consignadas y por la posibilidad de considerar su dimensión social, preferimos utilizar en este trabajo la noción de "liberacionismo" en el sentido propuesto por Michael Löwy quien utiliza el concepto de "cristianismo liberacionista" en lugar de "Teología de la Liberación" ya que "(...) este concepto es más amplio que el de 'teología' o que 'Iglesia', e incluye tanto la cultura religiosa como la red social, la fe y la praxis(...)". Löwy, Michael. (1999). Guerra de Dioses. Religión y Política en América Latina, México: Siglo XXI editores, p. 48.

${ }^{3}$ Utilizamos la noción de imaginario en el sentido propuesto por Baczko:

"(...) Los imaginarios sociales son referencias específicas en el vasto sistema simbólico que produce toda colectividad y a través del cual 'se percibe, se divide y elabora sus finalidades' (Mauss). De este modo, a través de estos imaginarios sociales, una colectividad designa su identidad elaborando una representación de sí misma; marca la distribución de los papeles y las posiciones sociales; expresa e impone ciertas creencias comunes, fijando especialmente modelos formadores como el de 'jefe', el de 'ciudadano', el del 'militante', etcétera. Así, es producida una representación totalizante de la sociedad como un 'orden' según el cual cada elemento tiene su lugar, su identidad, su razón de ser (...) Designar una identidad colectiva es, por consiguiente, marcar su 'territorio' y las fronteras de éste, definir sus relaciones con los 'otros', formar imágenes de amigos y enemigos, de rivales y aliados; del mismo modo significa proyectar hacia el futuro sus temores y esperanzas (...) De esta manera, el imaginario social es igualmente una pieza efectiva y eficaz del dispositivo de control de la vida colectiva, y en especial del ejercicio del poder. Por consiguiente, es el lugar de los conflictos sociales y una de las cuestiones que
} 
de opción por los pobres. Por último, también la integraron los laicos, que actuaron como referentes pastorales, animadores culturales, alfabetizadores en aquellos mismos lugares, por entender que el compromiso cristiano los compelía a la entrega abnegada por aquellos "hermanos" que vivían en situaciones de extrema pobreza y explotación.

Nos proponemos en este trabajo analizar la incidencia de la renovación de las sociabilidades católicas con posterioridad al CVII y el desarrollo de la corriente tercermundista. Procuraremos presentar y describir cuáles eran y en qué situación se encontraban los principales ámbitos de sociabilidad católica a comienzos de los años ‘60 y cómo influyeron en la conformación de redes que posibilitaron el diálogo entre individuos y grupos heterogéneos donde se destacaba la presencia juvenil.

Repasaremos las formas que adquirieron las iniciativas pastorales inspiradas en dicho ideario, subrayando especialmente el caso de los curas villeros, es decir del grupo de sacerdotes tercermundistas que desarrollaron su trabajo eclesial en las villas de emergencia radicadas en barrios marginales de la ciudad de Buenos Aires.

\section{De la herencia integralista a la efervescencia post-conciliar}

Ha sido objeto de gran interés e investigación el lugar de la Iglesia y del catolicismo como actor político destacado durante la década del '30 en el marco de los gobiernos militares que dominaron el período, así como, el ascenso del catolicismo integral y sus aspiraciones hegemónicas a nivel social. Precisamente, en ese marco se constituyeron y consolidaron algunas instituciones, espacios de formación y producción de conocimiento y publicaciones que se convirtieron en el entretejido sobre el cual se desplegaron las iniciativas intelectuales, eclesiales y pastorales que dieron impulso y perdurabilidad al desplazamiento del catolicismo a un lugar central del imaginario nacional. ${ }^{4}$

Fue en ese proceso que surgieron los Cursos de Cultura Católica (CCC) en 1922, la Revista Criterio, en 1928 y la Acción Católica Argentina (ACA) en 1931, en

están en juego en esos conflictos (...)". Baczko, Bronislaw. (1991). Los imaginarios sociales. Memorias y esperanzas colectivas, Buenos Aires: Nueva Visión, p. 28.

${ }^{4}$ Dos abordajes de esta cuestión pueden encontrarse en: Mallimaci, Fortunato. (1988). El catolicismo integral en la Argentina (1930-1946), Buenos Aires: Editorial Biblos; y Zanatta, Loris. (1996). Del Estado Liberal a la Nación Católica. Iglesia y Ejército en los orígenes del peronismo. 1930-1943, Buenos Aires: Universidad Nacional de Quilmes. 
torno a los cuales se forjaron las ideas, los debates de la elite católica y la formación de cuadros dirigenciales que actuaron dentro y fuera del catolicismo durante las décadas posteriores. Es que la característica fundamental del catolicismo integral era su fuerte inclinación por la acción social y el ejercicio de una militancia religiosa que no se conformaba con su presencia en la esfera estrictamente religiosa, sino por su aspiración de transformar la sociedad y el Estado de acuerdo a un modelo de cristiandad que sostenía la hegemonía del poder de la Iglesia católica sobre todo orden político y social y que se resumía en el lema "Restaurar todo en Cristo".

Aunque relativicemos los alcances que la preeminencia clerical tuvo sobre el laicado desde la constitución misma de la ACA, y la dificultad para mantener a flote a las distintas ramas ${ }^{5}$, es innegable el lugar que esta institución diseñada, en base al modelo italiano, tuvo en cuanto a que no sólo fue un espacio donde se expresó el compromiso religioso sino también fue el ámbito de socialización por excelencia en el interior del catolicismo proponiendo instancias de participación en la esfera pública no siempre permitidos en el ámbito político ${ }^{6}$

Como señala Beozzo, el ensanchamiento del espacio público dentro del catolicismo se produce paralelamente al cambio del modelo de fiel ya que el desarrollo de la ACA habría marcado el pasaje del "católico practicante a la insistencia en el católico militante". 7

"(...) Para los militantes de la AC, el trabajo sobre sí mismo no es suficiente: la
acción del movimiento apunta a la conversión de la sociedad en su conjunto. El
impulso que lanza al catolicismo fuera de las iglesias, y que lo lleva a ocupar el
espacio público, lo prepara también para una preocupación por el prójimo, que
es considerado el destinatario privilegiado del apostolado de la ACA. La
conciencia de la necesidad del trabajo social para lograr la salvación ("nadie se
salva solo") va a ubicar progresivamente el trabajo en los medios sociales en el
centro del compromiso de la AC. El deber del laico en tanto que miembro de la
lglesia es santificar el mundo. Este objetivo lleva a los miembros del
movimiento a participar en la evangelización de los ambientes sociales. (...)"

\footnotetext{
${ }^{5}$ Acha, Omar. "Notas sobre la evolución cuantitativa de la afiliación en la Acción Católica Argentina (1931-1960)". Documento de trabajo presentado en el Seminario de Discusión del Grupo de Religión y Sociedad en la Argentina Contemporánea (RELIG-AR) del Instituto de Historia Argentina y Americana "Dr. Emilio Ravignani" de la Facultad de Filosofía y Letras de la UBA y del Dpto. de Ciencias Sociales de la UNLu en diciembre de 2006.

${ }^{6}$ Mallimaci, Fortunato. "Movimientos laicales y sociedad en el período de entreguerrras. La experiencia de la Acción Católica en la Argentina" In Cristianismo y Sociedad, México, № 108, p. 35-71.

7 Beozzo, José Oscar. "La Iglesia frente a los estados liberales". In Dussell Enrique (Ed.). (1995). Resistencia y esperanza. Historia del pueblo Cristiano en América latina y el Caribe, San José de Costa Rica: DEI, p. 173-210.

${ }^{8}$ Giménez Béliveau, Verónica. (2005). "Sociabilidades de los laicos en el catolicismo en la Argentina. Un recorrido socio-histórico”. In Prismas, Revista de Historia Intelectual, № 9, UNQ, p. 220.
} 
A comienzos de los años '50, la ACA contaba con más de 70.000 militantes aunque los niveles de participación eran muy dispares entre las diferentes ramas, con una tendencia creciente a la deserción de militantes, lo cual dio lugar a numerosos documentos oficiales referidos a cómo revertir esta situación que también se producía en otros países. Esta percepción de debilitamiento llevó a la jerarquía eclesiástica local -en consonancia con la política vaticana- a dar un nuevo impulso a las organizaciones de laicos, así como, a apoyar la formación del Partido Demócrata Cristiano (PDC), en 1954. Pese a que la situación institucional y los límites que evidenciaba la presencia católica en su persistente anhelo de cristianizar la sociedad, un diagnóstico equívoco de Perón acerca de un supuesto peligro de reofensiva católica lo llevó a exacerbar la competencia con la Iglesia a partir de la creación de organizaciones y entidades que al igual que en el caso católico, aspiraban a una representación totalizadora de los diferentes grupos y sectores componentes de la sociedad. ${ }^{9}$

En el momento más álgido del enfrentamiento entre Perón y la Iglesia católica fueron los laicos organizados a través de los "Comandos Civiles" y de una comprobada pertenencia a la ACA quienes asumieron la defensa más encendida de la Iglesia a diferencia del comportamiento algo más tibio y dividido por parte de los obispos.

Consideramos, que la crisis que provocó en el catolicismo el enfrentamiento con el peronismo acentuó las aspiraciones de una mayor autonomía por parte de los laicos a la vez que realimentó su disposición para una actuación en la esfera pública que se condescendía con el espíritu belicoso y de cruzada en el que durante décadas aquellos laicos se habían formado y que sería muy difícil de desactivar por parte de la jerarquía con posterioridad a 1955.

Es en este contexto de un catolicismo lacerado por el enfrentamiento que se había suscitado con el peronismo que debe entenderse, el impacto, que sobre un escenario eclesial cuyos actores aún estaban ubicados en posiciones proclives al cuestionamiento y la crítica de lo que acontecía en el ámbito político, tuvo el CVII. En efecto, al conceder el concilio un lugar de protagonismo mucho mayor a los laicos y al

\footnotetext{
${ }^{9}$ Acerca de la crisis de la ACA y de las iniciativas eclesiásticas por reflotarlas a comienzos de los años cincuenta durante el gobierno de Perón pude consultarse el libro de Caimari, Lila. (1995). Perón y la Iglesia Católica. Religión, Estado y sociedad en la Argentina (1943-1955), Buenos Aires: Ariel.
} 
incitarlos, al mismo tiempo, a mantener y renovar su presencia pastoral en nuevos lugares de apostolado, coadyuvó a estimular la proliferación de iniciativas que superaran con creces las que surgían del universo clerical y jerárquico.

¿Cuáles fueron estas iniciativas? ¿Qué nuevas experiencias se generaron desde la ACA y quiénes fueron sus principales protagonistas?

Fueron primero los laicos los que estuvieron a la vanguardia de la etapa comprendida entre 1960 y 1966. Las parroquias dejaron de ser el lugar exclusivo o central de la participación cristiana, ya que se lo consideraba como insuficiente dada la enorme necesidad de extender su presencia a nuevos ambientes como los sindicatos, los colegios secundarios, las universidades estatales, las zonas rurales y urbanas pobres. Para ello, se planteaba la urgencia de pensar y definir una nueva Teología Pastoral adecuada a la actuación en estos ambientes menos transitados por los laicos católicos.

Se asistió por el lado de las ideas a una apertura que permitía elaborar propuestas desde la línea de la "Nueva Cristiandad" de Maritain ya presente en la formación del PDC; el social-cristanismo y personalismo comunitarista de Mounier, hasta la incursión en el uso de algunas categorías de análisis provenientes del marxismo. Sin embargo, esta influencia del pensamiento católico francés comenzó a ser cuestionada por algunos grupos que consideraban que debían buscarse respuestas que partieran de una elaboración de tinte nacional y fue en ese momento que ingresaron los autores forjistas y revisionistas. ${ }^{10}$

Entre las agrupaciones más activas de esta etapa podemos mencionar a aquellas que tenían una mayor autonomía respecto de la jerarquía y que actuaban en

\footnotetext{
${ }^{10}$ El forjismo fue un movimiento político disidente nacido en el seno del la UCR a mediados de los años '30 y que reivindicó el regreso a lo que definía como los postulados históricos de de esa fuerza política. Se caracterizó por su defensa del nacionalismo económico, su denuncia del imperialismo inglés y norteamericano en América Latina y se identificó con el liderazgo carismático y plebeyo de Hipólito Yrigoyen. Tras la aparición del peronismo un sector de FORJA se plegó al nuevo movimiento popular. El Revisionismo histórico es una corriente historiográfica nacida también a mediados de los años ' 30 . De orientación nacionalista y autoritaria proponía una lectura del pasado argentino a contrapelo de la versión liberal. Más tarde surgieron otras líneas internas más populistas e incluso de acercamiento a la izquierda pero desde una perspectiva nacional. Estas últimas fueron las más proclives a identificarse con el peronismo al que veían como potencialmente revolucionario al mismo tiempo que valorizaban positivamente la relación líder-masas populares que lo distinguían del resto de las fuerzas políticas argentinas.
} 
el terreno universitario, sindical o político como el PDC, el Humanismo y la Acción Sindical Argentina (ASA).

Por su parte, la ACA se caracterizó por la difusión de sus ramas especializadas: la JOC, la única que existía desde $1941,{ }^{11}$ se vio reforzada por la creación de la JUC, en 1958, de la JEC, que agrupaba a los estudiantes secundarios y el Movimiento Rural de Acción Católica (MRAC), creado también en 1958, pero que cobraría -como veremos mayor impulso- en los años ‘60.

También merece mencionarse la aparición de numerosos grupos de estudio y reflexión que se propusieron conocer a fondo los documentos conciliares y los debates teológicos puestos en diálogo con otras lecturas de raíz sociológica o histórica referida especialmente al contexto latinoamericano y argentino. Se trataba de grupos no del todo orgánicos pero sí cercanos a instituciones o referentes teológicos o sacerdotales con fuerte sensibilidad por la acción social.

Otros lugares donde comenzaron a gestarse nuevas discusiones referidas a la relación de la Iglesia y la sociedad en su conjunto fueron los seminarios. En el Seminario de La Plata enseñaban los jóvenes profesores Jerónimo Podestá, Eduardo Pironio y Antonio Quarracino quienes impulsaban la renovación litúrgica y bíblica. En el de Villa Devoto, Lucio Gera y Miguel Mascialino introducían en sus cursos la renovación de los estudios bíblicos y las ideas de Teilhard. ${ }^{12}$

\footnotetext{
${ }^{11}$ La JOC, que había sido fundada en 1925 por el sacerdote belga Joseph Cardjin, comenzó a funcionar en Argentina en 1941. Su propósito era evangelizar a los jóvenes obreros no sólo en las fábricas, sino también en la calle y en sus lugares de esparcimiento. El objetivo de la JOC no era crear sindicatos cristianos sino formar a los obreros según los principios cristianos para luego conquistar el medio social. El método de trabajo jocista se basaba en la pedagogía de la "Revisión de vida": Ver, juzgar, actuar. El punto de partida era pues el diagnóstico de la realidad y su análisis profundo para recién pasar a la acción. El método de la JOC significaba así, un cambio de óptica importante respecto del modelo italiano ya que la realización del apostolado no partía de dogmas o de la formación previa recibida en las parroquias sino de los problemas específicos de un ámbito pastoral concreto. Asimismo, acentuaba el ejercicio evangelizador por parte de los propios obreros, de ahí que nunca fueran fáciles las relaciones de la JOC y de sus asesores con la jerarquía ya que se experimentaba una permanente tensión entre las líneas de acción decididas por sus militantes y las directivas de la institución.

${ }^{12}$ Forni, Floreal. (1988). "Catolicismo y Peronismo III. Del aggiornamento a las vísperas (1955-1969)" In Unidos, no 18, Buenos Aires, abril de 1988.
} 
Por aquellos años se difundieron, también, los Campamentos Universitarios de Trabajo (CUT) organizados por el religioso jesuita José Luis Llorens (el padre "Macuca") por donde pasaron miles de jóvenes para quienes el compromiso cristiano se convirtió poco después en "opción por los pobres" en los barrios, en las villas, en las fábricas e incluso en el mundo rural. ${ }^{13}$ Sin embargo, previamente a este fenómeno, merecen mencionarse las experiencias misioneras que se impulsaron desde fines de los años '50 en provincias como San Tucumán, Salta y Jujuy, por parte de las ramas juveniles de la ACA. La actividad misionera tomó nueva fuerza a través de la Asociación Misionera Argentina (AMA), fundada por el obispo de Avellaneda, monseñor Di Pasquo. Para el verano de 1962, 18 equipos de 500 misioneros (sacerdotes, y laicos: estudiantes, agentes de salud y de promoción social) partieron hacia las provincias de Formosa, San Luis y Chaco. ${ }^{14}$

Por último, nos parece de gran importancia mencionar y describir algunas experiencias pastorales que pueden dar una idea más clara de cuáles fueron las prácticas concretas que asumieron los católicos argentinos que adhirieron a la línea renovadora post-conciliar.

Una de las regiones donde se plasmó con notable vigor el trabajo pastoral impulsado por el equipo de la Comisión Episcopal de Pastoral (COEPAL), fundada en 1966, fue en la región del Noreste (NEA) que nucleaba a 7 diócesis donde se destacaron las de reciente creación como Formosa, Posadas, Reconquista, San Roque y Goya que se sumaron a las más antiguas de Corrientes y Resistencia.

Entre 1963 y 1967 se organizaron allí las "Semanas de Pastoral del NEA" (SEPASNE) coordinadas por el canónigo francés Boulard y en el que se fue programando una pastoral de conjunto entre sacerdotes, religiosos, religiosas y laicos, junto a los pobladores del lugar, con el propósito de ayudar al movimiento rural que allí se venía gestando desde 1958 tras la creación del MRAC. Jóvenes asesores de formación universitaria viajaron a las distintas zonas rurales del país y del exterior donde recibieron una formación acorde a dicha problemática y varias congregaciones

\footnotetext{
${ }^{13}$ Mayol, Alejandro; Habegger, Norberto; Armada, Arturo. (1970). Los católicos posconciliares en la Argentina. 1963-1969, Buenos Aires: Editorial Galerna.

${ }^{14}$ Ver: Mayol-Habegger y Armada, op. cit y Llorens, José María (s.j.). (2000). Opción fuera de la ley, Buenos Aires: Grupo Editorial Lumen. Datos sobre estas experiencias misioneras pueden consultarse en los boletines de AICA correspondientes al período estudiado.
} 
religiosas femeninas eligieron dicho ámbito socialmente adverso para iniciar su labor religiosa de fuerte inclinación social. ${ }^{15}$

La experiencia de la COEPAL que se prolongó hasta 1973 tuvo la particularidad de ser un espacio que permitió la articulación de la reflexión teológica y la discusión intelectual desde la perspectiva de las Ciencias Sociales con prácticas pastorales que se inscribían dentro de las nuevas directivas conciliares. La primera mesa directiva de la COEPAL estaba integrada por los obispos Marengo, Zaspe y Angelleli. En torno a ellos se convocó a un equipo de colaboradores entre los cuales se destacaron Lucio Gera, Rafael Tello (ambos teólogos de la UCA); Justino O' Farell (sociólogo), Gerardo Farell y Juan Bautista Capallaro (integrante del Movimiento para un Mundo Mejor). Posteriormente, se sumaron otras figuras de destacada trayectoria como Alberto Sily (S.J. y director del Centro de Investigación y Acción Social de dicha orden: CIAS); Fernando Boasso (S.J.); Guillermo Sáenz (S.J. y asesor del MRAC); Mateo Perdía (Provincial de los Padres Pasionistas); Laura Renard (Superiora de las Hermanas Auxiliares Parroquiales de María); Aída López (Superiora de las religiosas de la Compañía del Divino Maestro) y Ester Sastre (Superiora de las Hermanas del Sagrado Corazón). Más tarde completaron el grupo Carmelo Giaquinta y Domingo Castagna.

Según Lucio Gera, tal vez el referente teológico más influyente de los católicos de línea renovadora y posteriormente del MSTM, las principales influencias intelectuales en las que se reconocía dicho equipo era, a nivel magisterial, la eclesiología del Pueblo de Dios de Lumen Gentium, a nivel teológico, la teología de las misiones y a nivel de la historia de las ideas latinoamericanas, Martí y Vasconcelos. Finalmente, estas lecturas entraban en diálogo con el revisionismo histórico, los planteos de las Cátedras Nacionales, el marxismo gramsciano y de la Escuela de Frankfurt y la literatura. pro-revolucionaria de los años sesenta. ${ }^{16}$

El desarrollo de la COEPAL nos remite a su vez, a otra experiencia pastoral que queremos consignar en este mapa de las sociabilidades católicas post-conciliares de

\footnotetext{
${ }^{15}$ Acerca de la inserción de congregaciones femeninas tercermundistas en medios populares de la Argentina puede consultarse: Touris, Claudia. "Entre Marianne y María. Los trayectos de las religiosas tercermundistas en la Argentina" In Andújar, Andrea; D’Antonio, Débora; Gil Lozano, Fernanda; Grammático, Karin, y Rosa, María Laura (compiladoras). (2009). De minifaldas, militancias y revoluciones. Exploraciones sobre los '70 en América Latina, Buenos Aires: Editorial Luxemburg, p. 5168.
}

${ }^{16}$ Gera, Lucio. (1990). “San Miguel, una promesa escondida”. (Reportaje). In Revista Voces, № 17. 
aquellos años: nos referimos al MRAC y su relación con el Movimiento de las Ligas Agrarias que se manifestaría con fuerte vigor una década más tarde pero que sin el trabajo previo de la militancia católica no podría comprenderse.

Aunque la presencia de la Iglesia católica en las regiones rurales de nuestro país se remonta a 1948 fue exactamente una década después cuando comenzó a cobrar un verdadero dinamismo al conformarse el MRAC y con el objeto de ampliar el trabajo regional a todas las diócesis del país con población rural. El trabajo propuesto era ayudar a los habitantes del lugar a desarrollar mejores estrategias de supervivencia y de economía familiar. Los maestros y los campesinos fueron los principales protagonistas del movimiento. Si bien al comienzo existió cierto grado de participación empresaria, a partir de 1964-65, el MRAC se fue perfilando hacia una identidad fuertemente campesina.

Hacia 1966, el MRAC tenía unos 300 grupos distribuidos en distintas provincias del país y editaba un periódico de aparición mensual llamado "Siguiendo la huella". Para ese momento se producían también materiales para la reflexión de las comunidades y se dictaban cursos de capacitación en el Instituto San Pablo, en la localidad de general Sarmiento, en la provincia de Buenos Aires a cargo de un equipo docente $y$ de consultores como el jesuita Alberto Sily muy cercano a este movimiento. ${ }^{17}$

El método de la JOC: "ver, juzgar, actuar" era el utilizado también por el MRAC que con posterioridad a la Conferencia de Medellín (1968) comenzó a asumir una postura cada vez más politizada. Su vinculación con otros movimientos campesinos similares, a nivel latinoamericano, a través del Movimiento Internacional de la Juventud Agraria y Rural Católica (MIJARC) al que estaba adscripto, llevó a sus participantes a conocer y discutir el método de educación liberadora de Paulo Freire que desde una pedagogía que se definía humanista y liberadora ponía el acento en la idea de que los oprimidos serían los propios artífices de su liberación del yugo ideológico que los condenaba a la marginalidad.

\footnotetext{
${ }^{17}$ Ver: "Alberto Sily: un cura con las Ligas Agrarias". In Lanusse, Lucas. (2007). Cristo Revolucionario, Buenos Aires: Ediciones B- Javier Vergara editor.
} 
La continuidad en la participación en seminarios internacionales sumada a la crisis que la política económica del gobierno militar estaba causando en los pequeños productores rurales y en las condiciones de trabajo de los campesinos, condujo a que ganaran terreno los planteos más radicales orientados a movilizar políticamente a sus bases formulados por parte de sus miembros y algunos asesores que entraron en conflicto con la jerarquía. Muchos de ellos alentaron y participaron en la creación de las Ligas Agrarias Chaqueñas hacia 1970. A medida que las reivindicaciones sobre el tema de la propiedad, la tenencia y la explotación de la tierra se generalizaban, al tiempo que se denunciaba el manejo de los monopolios extranjeros, los conflictos en la región del NEA se generalizaban. Hacia mediados de 1972, los miembros de la Ligas Agrarias perdieron el apoyo de uno de los obispos que más había incidido en el crecimiento de esta experiencia: Monseñor Italo Di Stefano, obispo de Sáenz Peña. El desenlace se aproximaba: el 16 de mayo de 1972 la Conferencia Episcopal excluyó al MRAC de la Iglesia. Sus militantes continuaron, sin embargo, en las Ligas Agrarias, o migraron hacia agrupaciones políticas de orientación peronistas. Los casos más extremos derivaron en su vinculación con la lucha armada.

El último de los grupos surgidos como otra de las ramas especializadas de la ACA al que queremos referirnos por su importancia relativa, y que también evolucionó hacia una radicalización similar a la de otros que habían eclosionado al calor de la renovación conciliar, fue la JUC. Esta rama que agrupaba a los estudiantes universitarios había nacido hacia 1958, basada en una concepción bastante tradicional, que ligaba su trabajo apostólico en el terreno universitario, a partir de una estrecha vinculación y dependencia con la jerarquía, recibiendo una formación más bien doctrinaria y apologética. Sin embargo, apenas comenzados los años '60, -tal como lo señalan varios autores- los jucistas comenzaron a plantearse la necesidad de adecuar su trabajo pastoral procurando dar respuestas más pertinentes al tipo de problemas que se discutían sobre la realidad del país. En 1963, se llevó a cabo un importante encuentro universitario en Tandil donde tras un primer diagnóstico sobre la situación argentina y latinoamericana, los jucistas denunciaron los dos polos ideológicos en los que -según ellos- estaba encerrado el movimiento universitario: laicismo contra libertad de enseñanza y democracia contra Revolución Cubana. Comenzaron a cuestionarse las premisas desarrollistas a favor de lecturas que acentuaban la inminencia de la 
liberación del Tercer Mundo y el cambio de estructuras, proceso en el que según los dirigentes de la JUC tenía que producirse con la participación de la Iglesia. ${ }^{18}$

Como apunta Politi:

“(...) la profundización de las premisas conciliares de diálogo con el mundo, valoración de la historia, renovación eclesial, protagonismo del laico, etc. llevaban a los jóvenes de la JUC a una búsqueda concreta de su lugar en la transformación de la sociedad. La influencia de autores como Teilhard de Chardin o Mounier los llevaba a desechar la opción de incorporarse a partidos 'cristianos' u otro tipo de organizaciones confesionales. De ahí sus intentos de discernir cuál sería el ámbito de su compromiso. En este contexto se ubican los diálogos entre cristianos y marxistas (buscados en realidad por el propio Partido Comunista), que no tuvieron especial trascendencia, pero que simbolizan una mentalidad y una búsqueda (...)" ${ }^{19}$

Una fuerte incidencia sobre esa mentalidad y esa búsqueda tuvieron los sacerdotes que actuaron como asesores de la JUC en las diferentes facultades de la UBA: Carlos Mugica en la Facultad de Ciencias Económicas y en la Facultad de Medicina; Alejandro Mayol en la Facultad de Farmacia y Bioquímica y en la de Odontología; Pedro Geltman en la Facultad de Ingeniería y Rodolfo Ricciardelli en la Facultad de Arquitectura.

Desde la JUC se propiciaba, cada vez con mayor énfasis el trabajo social. Había estudiantes jucistas de la carrera de Sociología de la UBA colaborando en las experiencias de Gino Germani en Dock Sud. $Y$ otros que decidieron sumarse al proyecto pastoral que alguno de sus asesores comenzaron a desarrollar en las villas de la ciudad de Buenos Aires, como Rodolfo Ricciardelli y Carlos Mugica. ${ }^{20}$ En 1966, sin embargo, la intervención de las universidades tras el golpe del general Onganía precipitó a la JUC hacia el final, ya que además fue intervenida por la jerarquía, razón por la cual desaparecía aquélla como instancia válida de participación católica dentro de la universidad. El acento cada vez más político de sus acciones, sumada a la crisis que provocó el abandono del sacerdocio por parte de algunos de sus asesores, había tensado al extremo la relación con las autoridades eclesiásticas de las que finalmente

\footnotetext{
${ }^{18}$ Una descripción bastante precisa de este proceso puede consultarse en Mayol-Habegger- Armada, op. cit. ; Giménez Béliveau, op. cit. y Moyano, Mercedes. (1992). "Organización popular y consciencia cristiana, la década del '60". In A.A.V.V. 500 años de cristianismo en Argentina, Buenos Aires: CEHILA.

${ }^{19}$ Politi, Sebastián. (1992). Teología del Pueblo. Una propuesta argentina para Latinoamérica, Buenos Aires: Ediciones Castañeda-Editorial Guadalupe, p. 135-136.

20 Entrevista a Francisco del Campo, ex-presidente de la JUC argentina y dirigente de la JEC Internacional en la década de 1960. Realizada por Claudia Touris el 28 de febrero de 2002 en la ciudad de Buenos Aires.
} 
dependían. Fue así, que mayoritariamente, las ramas especializadas de la ACA se convirtieron en plataformas de despegue del catolicismo ya que en la medida en que el compromiso que los jóvenes habían asumido en tanto cristianos vio obturados todos los canales de institucionalización dentro de la Iglesia, rompieron los lazos que los unían a ella y prosiguieron un trayecto que los sumiría de lleno en la actividad social y política. Muchos ex-jucistas se incorporaron a agrupaciones políticas, otros lo hicieron en ambientes populares como las villas miseria de Buenos Aires o promoviendo publicaciones como la Revista Tierra Nueva.

\section{Sociabilidades católicas transformadas: referentes intelectuales y eclesiales, redes tercermundistas y populismo clerical}

Un aspecto significativo al que queremos hacer referencia es que nuestro interés en describir los cambios en las formas de sociabilidad católicas renovadoras y tercermundistas se orienta a explicar y precisar mejor su real incidencia en la conformación de agrupaciones armadas. Partimos de la premisa de que ninguna de estas cuestiones puede analizarse sin darle centralidad al peso decisivo que cobró en aquellas décadas la irrupción de una cultura juvenil, de características muy particulares. Es este encuadre el que nos lleva a señalar la importancia de identificar los ámbitos de sociabilidad católicos, propiamente dichos, al mismo tiempo que reubicarlos en un mapa más complejo en el que existían sociabilidades más amplias propias de la cultura juvenil en su conjunto y de las cuales se nutrieron obviamente también los jóvenes católicos. 
"Sociabilidades católicas post-conciliares

\section{Esquema de redes y referentes de sociabilidad tercermundista}

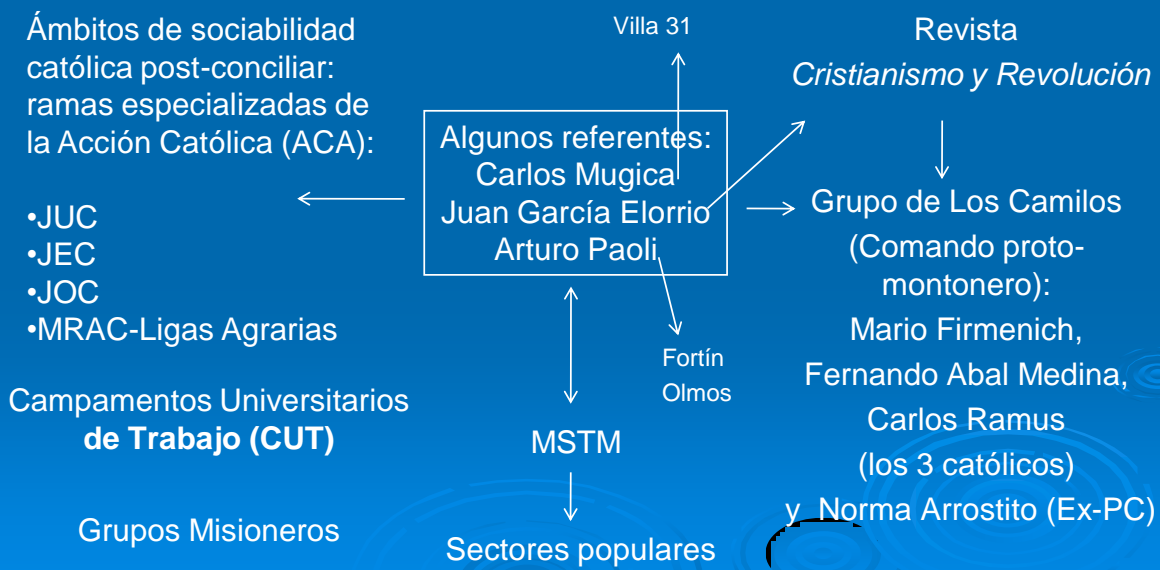

Revista

Cristianismo y Revolución

A partir del inicio de la Revolución Argentina y de una serie de conflictos que signaron las relaciones intraeclesiales, la crisis de la ACA y la emergencia del MSTM (1967), una porción muy grande de los católicos se radicalizaron políticamente. Había llegado el momento del "compromiso político", etapa que se extendería entre 1967 y $1973,{ }^{21}$ y que se caracterizó por un desplazamiento del dinamismo eclesial a manos de los clérigos tercermundistas quienes se convirtieron en los referentes máximos de laicos, religiosas, grupos de estudio, obreros, estudiantes que se identificaban con la opción revolucionaria de parte de los cristianos.

Ciertamente, dos caras de un mismo fenómeno pero con derivaciones muy diferentes fue la ligazón del catolicismo con el horizonte revolucionario que parecía agitarse sobre los países latinoamericanos merced al éxito de la Revolución Cubana y que se expresó en las redes afines a la

${ }^{21}$ Politi, Sebastián, op. cit,

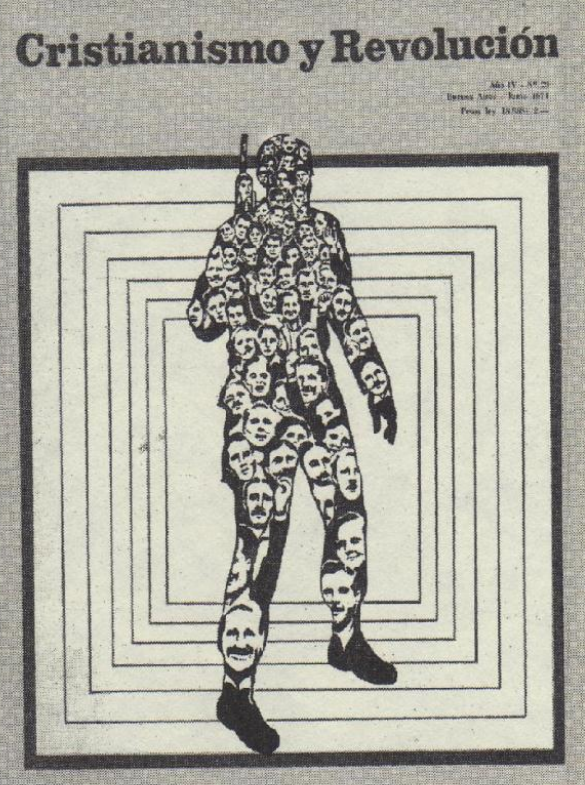

LA HORA DEL PUEBLO EN ARMAS 
Revista Cristianismo y Revolución, por un lado, y en torno al MSTM, por otro.

La revista Cristianismo y Revolución fue fundada por el ex- seminarista Juan García Elorrio y encarnó la corriente más radicalizada del cristianismo liberacionista argentino.

El caso de $C$ y $R$ estuvo directamente vinculado con la figura de su fundador, Juan García Elorrio, un ex-seminarista de la diócesis de San Isidro, que experimentó una trayectoria de vertiginosa radicalización en la que confluyeron su raíz cristiana post-conciliar, su acercamiento al peronismo revolucionario y su opción por la lucha armada.

Ampliamente vinculado con distintas redes católicas y grupos de reflexión orientados a la discusión sobre la teología del concilio, dio inicio en septiembre de 1966, al primer número de la revista, cuya publicación se extendería hasta 1971 con un total de 30 números y 3 ediciones especiales.

No nos interesa aquí analizar las ideas, las etapas, ni los planteos de la publicación, sino más bien, resaltar que se trató de un espacio de vinculación entre grupos cristianos, marxistas y peronistas revolucionarios, por citar a los núcleos ideológicos más potentes y que derivó en la adopción de prácticas religiosas y políticas no necesariamente compatibles o que incluso dieron lugar a escisiones y cambios de rumbos que evidenciaban que este tipo de experiencias compartidas podían ser de 
carácter transitorio u operar como puentes o escenarios de pasaje hacia otros lugares y posiciones.

Por ejemplo, pocas vinculaciones le quedaron a García Elorrio y a $C$ y $R$ con figuras como Jorge Mejía (director de Criterio) o Eduardo Pironio (Rector del Seminario de Buenos Aires), por citar sólo dos de los principales referentes del catolicismo postconciliar con los que García Elorrio había compartido reuniones en el Centro de Estudios "Diálogos", por él creado a mediados de 1965, a diferencia de lo que sí ocurriría con el padre Arturo Paoli (animador de las Juventud Demócrata Cristiana de Santa Fe y organizador de la Cooperativa de Hacheros Fortín Olmos, en el norte de dicha provincia) y Casiana Ahumada a quien allí conoció y a la que se ligó intelectual y afectivamente. En ese ámbito, se había relacionado también con John William Cooke y Sabino Navarro. ${ }^{22}$ Otra figura cercana en los primeros tiempos a García Elorrio fue el sacerdote Carlos Mugica (MSTM).

Otro ejemplo que ilustra el lugar de $C$ y $R$ como puente que posibilitaba pasajes y retornos de los individuos y grupos que allí se interconectaban es el de los fundadores de Montoneros, que llegaron a García Elorrio a través de su relación con el padre Carlos Mugica cuando éste actuaba como asesor de la JEC en el Colegio Nacional Buenos Aires, de la que formaban parte. Ellos eran: Fernando Abal Medina, Carlos Ramus y Mario Fimenich. En febrero de 1966, los dos últimos habían participado de una experiencia misionera en Tartagal, al norte de Santa Fe, que los introdujo de una manera muy directa en la discusión de la legitimidad de los cristianos de usar la violencia en contextos de opresión política y social.

La muerte del cura guerrillero Camilo Torres, acaecida en Colombia en 1964, impactó fuertemente en la sensibilidad de estos jóvenes que comenzaron a pensar que el cruce del cristianismo y la revolución sería inevitable. ${ }^{23}$ Precisamente, la opción por la acción armada se resolvió cuando estos jóvenes se reunieron en torno a Juan García Ellorrio en el momento en que un grupo de la revista directamente dirigido por éste decidió organizar una célula armada que derivó en la formación del comando protomontonero Camilo Torres, al que se sumó también la ex-militante del Partido

\footnotetext{
${ }^{22}$ Morello, Gustavo. (2006). "Apuntes sobre la vida de García Elorrio". In Lucha Armada en la Argentina, Año II, № 7.

${ }_{23}$ Ver: Anguita, Eduardo y Caparrós, Martín. (1997). La Voluntad. Una historia de la militancia revolucionaria en la Argentina 1966-1973. Tomo 1, Buenos Aires: Grupo Editorial Norma.
} 
Comunista (PC) Norma Arrostito, compañera de Abal Medina y que tuvo su primera aparición pública en mayo de 1967. Paradójicamente, este momento coincidió con el alejamiento de García Elorrio y "Los Camilos" del cura Mugica, por sus discrepancias en torno a los métodos de la lucha revolucionaria y que se reproducirían más tarde en la ruptura de Firmenich, Abal Medina, Ramus, Arrostito y Maza, con García Elorrio, a mediados de 1968, ante la decisión de éstos de avanzar mucho más rápidamente que aquél en la formación de un grupo guerrillero. ${ }^{24}$

Pero no todos los jóvenes católicos se radicalizarían tan rápidamente ni se integrarían a formaciones guerrilleras. De hecho esta decisión generó tensiones y distanciamiento entre ellos y algunos sacerdotes tercermundistas que habían sido sus mentores como muestra el ejemplo de Mugica y los Montoneros.

El segundo caso a través del cual pretendemos explicar de qué manera se manifestó una de las formas de sociabilidad católica de orientación tercermundista es el de la militancia sacerdotal en las villas de emergencia de la ciudad de Buenos Aires, particularmente de los que actuaron en la Villa 31 de Retiro.

Afirmamos que el caso de los curas villeros fue una experiencia más típicamente representativa del catolicismo tercermundista argentino. Es decir, una experiencia en la que sus prácticas predominantes no se desplazaron hacia la acción armada como el caso consignado de $C$ y $R$. A nuestro criterio, ésta se trató más bien de una vertiente que aunque fuertemente impregnada de un bautismo ideológico propio del catolicismo intransigente, se redefinió rápidamente hacia una propuesta que privilegió su opción político-militar sobre la político-religiosa del MSTM y del catolicismo tercermundista en general. El carácter redentor que el grupo de $C$ y $R$ le atribuyó sin ambages a la violencia estuvo presente sólo discursivamente en el núcleo mayoritario del catolicismo tercermundista donde sólo excepcionalmente se hizo uso de la opción armada.

Analizaremos las relaciones que se establecieron entre el campo de la militancia religiosa y el de la militancia política y que se expresó a través de una compleja red articulada en torno a la emergencia y la actuación del MSTM.

24 Donatello, Luis. (2003). "Religión y Política: las redes sociales del catolicismo postconciliar y los Montoneros. 1966-1973" In Estudios Sociales. Revista Universitaria Semestral. Año XIII, № 24, Universidad Nacional del Litoral, primer semestre de 2003. 
El ámbito de las villas pues fue otro de los escenarios de trabajo al que se lanzaron los militantes católicos post-conciliares. Allí también, desde mediados de los años '60, puede detectarse la presencia de nuevos actores que aunque procedieran de campos en principio diferenciados, como el político y el religioso, también coincidían en el hecho de estar imbuidos de una misma mística y sobre todo por la convicción de que los pobres podían ser los artífices de un mundo nuevo y liberador de todas las opresiones.

La confluencia de los habitantes de las villas, con los jóvenes peronistas y los curas tercermundistas dio lugar a una experiencia inédita de concientización política y social que tuvo su cenit en 1973.

Una de nuestras hipótesis es que el trabajo que los curas tercermundistas desarrollaron en las villas porteñas fue el eje potenciador de la radicalización social y política que asumieron las reivindicaciones de los habitantes de las villas. Y además fue la bisagra que unió a los villeros con los sectores juveniles del peronismo sobre los cuales los clérigos tercermundistas tuvieron un gran ascendiente. ${ }^{25}$

En lo que respecta a las villas es importante recordar que entre 1955 y 1976 estos asentamientos se convirtieron en uno de los objetivos de las políticas públicas, tanto a nivel nacional como municipal, y que la alternancia entre la represión, planes de erradicación y asistencialismo, fue el tono que marcó la relación entre las instituciones estatales y los pobladores de las villas. De todas ellas, la que ganó mayor protagonismo fue la Villa de Retiro que por ubicación, cantidad de habitantes y nivel de organización fue la más relevante a la hora de analizar la cuestión que nos interesa.

La mayoría de los habitantes de las villas eran migrantes internos y extranjeros de países limítrofes que tenían cierta experiencia de participación vecinal y en buena medida se sentían identificados con el imaginario de la sociedad del bienestar y la movilidad social ascendente que el peronismo había instalado entre los sectores populares durante la década del '40. Este dato no es menor ya que es interesante ver

\footnotetext{
${ }^{25}$ Touris, Claudia. (2006). "Militancia política y religiosa en las villas de la ciudad de Buenos Aires (19671976)" In CD de Actas del I Simposio sobre Religiosidad, Cultura y Poder. GERE-PROHAL- Instituto Ravignani, FFyL (UBA), 22 y 23 de junio de 2006.
} 
cómo se va produciendo un desplazamiento ideológico de carácter reformista a otro predominantemente contestatario y revolucionario o bien pensar hasta qué punto los villeros se identificaron y asumieron las consignas y las reivindicaciones que de algún modo le fueron transmitidas por los curas tercermundistas y la Juventud Peronista (JP). Este punto podría ser una de las claves para medir los alcances de esta experiencia vertiginosa y fugaz.

Nos interesa explicar pues ¿Cómo se vivió en las villas la ola de contestación social que invadió la sociedad y la política argentina después del Cordobazo? Y también ¿de qué manera se trastocaron y se politizaron las aspiraciones de sus habitantes? En suma ¿cómo se integraron los villeros a los proyectos de poder en pugna dentro del peronismo, dentro del catolicismo y dentro de lo que en aquellos años se denominaba el "campo popular"?

Uno de los actores fundamentales a la hora de emprender una reconstrucción de lo acontecido en las villas, fue la Iglesia Católica o mejor dicho el MSTM.

EI MSTM fue un colectivo sacerdotal que abrazó la opción por los pobres y que aceptó la legitimidad de la violencia para luchar contra los regímenes dictatoriales e imperialistas. También orientó su acción pastoral al acompañamiento de los jóvenes, de los obreros, los campesinos al mismo tiempo que se fomentaban experiencias innovadoras que tenían el propósito de que los laicos asumieran el compromiso cristiano indefectiblemente ligado a la participación social y política. ${ }^{26}$

Hacia 1965, el padre Carlos Mugica inició su actuación pastoral en la Villa del Retiro al fundar la capilla de Cristo Obrero, ejemplo que fue imitado por otro grupo de sacerdotes en otras villas de la ciudad y que 1969 quedó legitimada por la autorización del Arzobispo Coadjutor Juan Carlos Aramburu para desarrollar una pastoral especialmente orientada al trabajo en las villas.

\footnotetext{
${ }^{26}$ Martín, José Pablo. (1992). El Movimiento de Sacerdotes para el Tercer Mundo. Un debate argentino, Buenos Aires: Ediciones Castañeda-Editorial Guadalupe.
} 


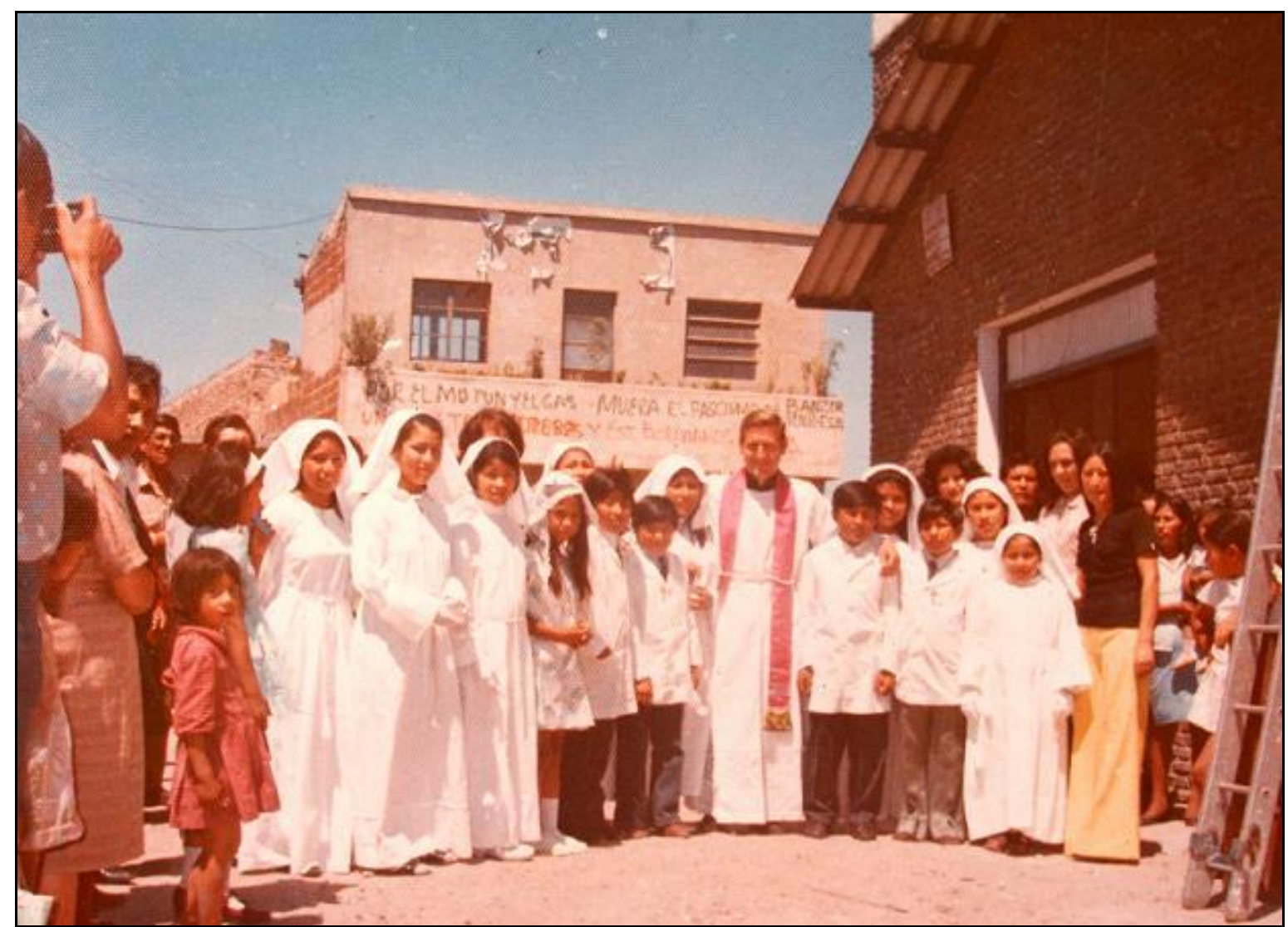

Carlos Mugica en una celebración religiosa en la Villa 31 de Retiro (ciudad de Buenos Aires) a comienzos de los años '70.

EI MSTM se caracterizó por su alto perfil en la escena pública a través de declaraciones, documentos, ayunos, participación en ollas populares, huelgas, etc.

Dos buenos ejemplos de este tipo de intervenciones fueron la declaración de diciembre de 1968, oponiéndose al "Plan de erradicación de villas" lanzado por el presidente de facto, General Juan Carlos Onganía y el documento de noviembre de 1969, en el que se repudiaba la iniciativa de Onganía de consagrar el país al Inmaculado Corazón de María y se denunciaba la instrumentalización de los sentimientos religiosos del pueblo y en especial del culto mariano. ${ }^{27}$

Se impugnaba así dentro del propio catolicismo la alianza entre la espada y la cruz y el mito de la "nación católica", apoyado en la imagen triunfante de "Cristo Rey" se redefinía en la propuesta tercermundista de un "Cristo Obrero".

${ }^{27}$ Bresci, Domingo. (Compilación, presentación y notas). (1994). Movimiento de Sacerdotes para el Tercer Mundo, Buenos Aires: Centro Salesiano de Estudios San Juan Bosco. Centro Nazaret. 
En diciembre de ese mismo año, bajo la consigna "Transformar las villas en barrios obreros", los curas tercermundistas realizaron la primera peregrinación a Luján donde evidentemente la ritualidad tradicional se vio resignificada en un nuevo molde donde la religiosidad popular se potenciaba en una práctica religiosa en la cual la fe y la política se ensamblaban con un propósito de transformación social. ${ }^{28}$

Con respecto a la relación religiosidad popular-cristianismo revolucionario podría decirse que en el caso argentino se llevó a cabo un trabajo pastoral que si bien priorizó en un principio lo asistencial y promocional sobre lo estrictamente religioso, el apego de los villeros a ciertas manifestaciones de una religiosidad más respetuosa de lo ritual y de una concepción más tradicional del rol sacerdotal los llevó a revalorizar estos elementos mediante un planteo teológico-pastoral en clave culturalista: la Teología del Pueblo enunciada por Lucio Gera y Rafael Tello.

La simbología religiosa de carácter popular se vio revestida así de una finalidad donde fe y política se unían con un propósito liberador. La fe se articulaba en una configuración singular donde íconos tales como la "virgencita gaucha" de Luján podían convivir con Camilo Torres, el cura guerrillero y "Santa Evita".

Veamos ahora cómo entraron en escena los sectores juveniles provenientes del campo político.

Si bien desde 1955 puede reconocerse que había un importante trabajo de base del PC, el salto cualitativo y cuantitativo se produjo hacia 1970 con la irrupción en dicho ámbito de jóvenes universitarios vinculados al peronismo pero que en buena parte tenían formación cristiana.

¿Cuál fue la relación entre los sacerdotes tercermundistas y los jóvenes que actuarían en las villas y más especialmente con la militancia peronista revolucionaria de adscripción montonera?

Como ya mostramos, Mugica había sido asesor de la JEC en el Colegio Nacional Buenos Aires- en la que participaban Carlos Ramus, Fernando Abal Medina y

${ }^{28}$ Touris, Claudia. "Militancia política y religiosa...", op. cit. 
Mario Firmenich. $\mathrm{Y}$ todos estos estudiantes habían participado en una experiencia misionera en el norte del país (Tartagal) que parece haber sido decisiva para su radicalización política.

Asimismo, otros curas integrantes del MSTM habían actuado como asesores de la JUC en las distintas facultades de la UBA.

La experiencia de los CUT extendidos a lo largo del país por iniciativa del religioso jesuita "Macuca" Llorens fue otro de los ámbitos donde se fue articulando una concepción religiosa asociada al trabajo social y político.

Finalmente, debemos volver a mencionar a la figura García Elorrio y su revista $C$ y $R$ donde confluyeron cristianos y marxistas un poco desencantados de las experiencias más ceñidas a las directivas institucionales o partidarias. De este grupo saldría el comando protomontonero Camilo Torres integrado por los jóvenes antes mencionados y cuya aparición también consignáramos.

El año 1971, fue clave en la experiencia villera, en la medida en que el peronismo revolucionario se lanzó a organizar y movilizar políticamente todos los lugares de militancia popular con el objeto de sustraerlos del control de la "burocracia" del partido mediante la creación de las Unidades Básicas Revolucionarias (UBR) con el objeto de articular la militancia política de superficie con la lucha armada. Fue así, que la Villa del Retiro se transformó en un hervidero en el que participaban los curas tercermundistas, la JP, intelectuales y artistas. El propio Perón al regresar del exilio se reunió especialmente con el MSTM y visitó la Villa 31.

Con vistas a las elecciones de 1973, los dirigentes villeros crearon el Movimiento Villero de Liberación Nacional (MVLN) que logró reconocimiento oficial y que se inscribió dentro de la campaña electoral que apoyaba la candidatura de Cámpora. A mediados de ese año, los curas tercermundistas y la JP promovieron la formación del Movimiento Villero Peronista (MVP), conformado por diferentes mesas de trabajo que defendían los reclamos villeros ante los representantes del Estado.

El máximo momento de protagonismo político por parte de los dirigentes villeros fue durante la "primavera camporista", es decir durante el breve gobierno del presidente 
Héctor Cámpora, apoyado por los distintos sectores del peronismo revolucionario y definidos como la "Tendencia" pero luego desplazado por el propio Perón, una vez que desenmascara su abierto apoyo a los grupos de la derecha peronista encarnados en la burocracia sindical y los sectores tradicionales del ala política del movimiento y los comandos de ultraderecha sedientos de revancha contra los grupos de izquierda juveniles, intelectuales y de base.

Los entrenados cuadros de la JP tuvieron un alto apoyo entre los habitantes de las villas: campamentos infantiles para los niños, campañas de alfabetización, dispensarios, brigadas de trabajo, asesoramiento a extranjeros indocumentados, ayuda en proyectos de autogestión, etc.

Pero esta efervescencia y optimismo respecto de los reclamos exitosos canalizados a través de la Comisión Municipal de la Vivienda (CMV) controlada por sectores de la "Tendencia" pronto tuvo su freno por el lado del Ministerio de Bienestar Social (MBS) dirigido por José López Rega quien lanzó el Plan Alborada cuyo objeto era erradicar las villas al mismo tiempo que se desconocieron las mesas de trabajo existentes y se censantearon a muchos militantes y cuadros técnicos de la CMV.

La primavera camporista o lo que podríamos llamar la "ilusión de la política" en clave católica y peronista había llegado a su fin y con ella las esperanzas de transformación social encarnada en la experiencia militante de curas tercermundistas, peronistas de izquierda y habitantes de las villas.

La ruptura de Perón con los Montoneros acaecida el 1 de mayo de 1974, el asesinato del padre Mugica pocos días más tarde y la división de la JP, contribuyeron al debilitamiento y a la pronta extinción del MVP.

El golpe de 1976 no sólo terminaría con cualquier nuevo intento reivindicativo de las organizaciones villeras sino que lanzó el más sistemático plan de erradicación y de represión para las villas de emergencia.

Por último, consideramos que en esta experiencia de confluencia de la militancia política y la religiosa la frontera entre ambos campos se tornaba bastante difusa en la 
medida en que se desarrollaron discursos y prácticas donde lo religioso quedó subsumido en lo político y lo político se tiñó de un tono profético y trascendentalista.

Los curas tercermundistas que pueden ser vistos como intelectuales y también como gestores de experiencias pastorales y políticas concretas contribuyeron a fortalecer una red compleja donde se articularon las vanguardias y las bases populares. Este rol del MSTM parece confirmarse en alguna de las últimas investigaciones referidas a los grupos que en distintas regiones del país convergieron para dar origen a la agrupación Montoneros y que tenían inicialmente una fuerte formación católica. ${ }^{29}$ Sin embargo, la experiencia de los curas villeros estuvo relacionada más bien con la militancia peronista que aunque se encuadraba dentro de los sectores juveniles del peronismo había optado por el trabajo de base y no por participar en la lucha armada, distinción que no es un dato menor, para matizar las visiones historiográficas que en parte criticamos, además de sugerir nuevas líneas de trabajo que exploren no sólo las afinidades electivas sino también las tensiones y las diferencias entre el imaginario católico tercermundista y el de los Montoneros.

El rescate que hizo el MSTM de la religiosidad popular y su idealización del saber popular también leído en ese registro por muchos protagonistas políticos de aquellos tiempos, contribuyó a anclar su imaginario de "liberación" en el movimiento político que mejor parecia haber representado las distintas manifestaciones de lo popular: el peronismo.

Se fue conformando pues un imaginario revolucionario en el que se cristalizó un núcleo de gran sensibilidad hacia las profecías de acontecimientos apocalípticos que podrían resumirse en la convicción que tenían -por ejemplo- al anunciar que el capitalismo sería destruido y que la voluntad y la determinación revolucionaria debían forzar ese fin mediante la violencia revolucionaria. De la Revolución nacería el "hombre nuevo". Aún así cabe destacarse que dentro del MSTM convivieron varias líneas internas con diversas orientaciones ideológico-político y pastorales. Evidentemente, los curas villeros se inscribieron dentro de un liberacionismo católico en clave populista de izquierda más que marxista como se dio en otras vertientes del MSTM o en grupos laicos al estilo de $C$ y $R$.

\footnotetext{
${ }^{29}$ Lanusse, Lucas. (2005). Montoneros. El mito de sus 12 fundadores, Buenos Aires: Javier Vergara editor.
} 
En cuanto al MVP nos queda también la sospecha de que el imaginario revolucionario de los habitantes de las villas se relacionara más bien con un retorno al peronismo clásico que con el modelo al que aspiraban los demás actores analizados en este trabajo quienes estaban indudablemente más identificados con el imaginario más heterodoxo pero radical de la Nueva Izquierda. Y en parte por ello -y dejando de lado la incidencia de la represión de la dictadura militar-, la militancia protagonizada por los propios villeros se tornaría casi inexistente al mismo tiempo que la actuación de los curas villeros se replegaría hacia prácticas estrictamente religiosas más ceñidas a un tipo de ritualidad y religiosidad popular de gran aceptación en los ambientes populares y menos conflictiva al interior de la institución eclesial.

\section{Consideraciones finales}

Nos propusimos en este trabajo dar cuenta de la relación entre las formas de sociabilidad católicas posteriores al CVII y su incidencia en la confluencia de las identidades político-religiosas que emergieron en algunos grupos que se inscribieron dentro de la corriente tercermundista o liberacionista. Elegimos analizar en detalle dos experiencias ("Cristianismo y Revolución" y Curas Villeros) que aunque presentaban muchos rasgos de similitud, constituyen más bien, -a nuestro criterio- dos ejemplos distintos de vinculación con la política y del tipo de radicalización al que podían llegar los sectores tercermundistas del catolicismo argentino. Indudablemente, ninguna de estas experiencias podrían entenderse sin haber explicado cuáles fueron los ámbitos, los grupos y las personas por los que los actores de esta historia habían transitado y se habían relacionado. Es decir, comprender qué transformaciones se habían producido en el mundo católico en los años '60 y qué ideas y prácticas se habían introducido en dichos ambientes. Parte de lo potencialmente disruptivo de este proceso fue que su desarrollo coincidió con un momento histórico impregnado de un imaginario revolucionario al que se suscribieron miles de jóvenes dispuestos a transformar estructuralmente la realidad. Otros fenómenos asociados a la persistencia de una cultura política autoritaria propensa a los antagonismos acérrimos, en una lógica de exclusión total del adversario, reforzó, la convicción extremista de muchos de aquellos protagonistas que concluyeron que la única salida era la del fusil. 
Sin duda, el catolicismo integral y su dispositivo institucional había sido un factor no desdeñable a la hora de generar un tipo de fiel-militante que por definición no era un sujeto prescindente de los avatares políticos ni de aquello que históricamente la Iglesia católica había bautizado como la "cuestión social".

El enfrentamiento con el peronismo permitió exhibir toda la furia de esa militancia laica dispuesta a la acción adquiriendo un protagonismo que todavía no se había sosegado cuando el CVII redefinió el lugar y los escenarios para desarrollar su apostolado. Es decir, un nuevo ropaje de ideas e iniciativas pastorales para un nuevo impulso de cristianización sobre una sociedad y un mundo moderno altamente secularizado.

Nuestra descripción de las formas de sociabilidad católica post-conciliares nos induce a situarlas como el espacio "en disponibilidad" por excelencia que existía para el ingreso de los jóvenes pertenecientes al mundo católico. Sin embargo, se trataba de sociabilidades plurales y en permanente dinamismo, razón por la cual posibilitaron la relación con otros universos culturales y políticos pudiendo generar pasajes de salida, de retorno o consolidar permanencias en dichos espacios que eran también núcleos identitarios.

La frecuentación de clubes, parroquias, ateneos, grupos estudiantiles convocados por inquietudes intelectuales, sociales o artísticas, la participación en ciclos de cine debate, grupos teatrales o talleres de teatro eran algunos de los ámbitos donde esta cultura juvenil se exhibía y se vinculaba por redes sociales afines. ${ }^{30}$ Allí, las fronteras iniciales se tornaban difusas a partir de la expansión de una sensibilidad común que potenciaba las ya aludidas convicciones compartidas y que sólo en los casos de una fuerte inclinación política derivaron en salidas radicalizadas.

Consideramos haber demostrado así que las formas de sociabilidad católica de ese entonces eran amplias y diversas, razón por la cual consideramos más pertinente

\footnotetext{
${ }^{30}$ Alicia Canizo, una militante católica vinculada en su etapa infanto-juvenil a distintos grupos de la ACA y que hiciera trabajo de base en la villa del Retiro a comienzos de los años '70 junto al sacerdote jesuita José Meiseigeir (MSTM) recuerda el importante rol que tuvieron para estos grupos juveniles la organización de recitales, predominantemente folklóricos, en sus años previos de estudiante secundaria. En ellos participaban no sólo los estudiantes pertenecientes a la JEC sino también los delegados de centros estudiantiles de colegios estatales como el Normal № 4 y el Otto Krause. Entrevista realizada por Claudia Touris (18-04-2007).
} 
hablar de sociabilidades, entendidas éstas, como lugares donde se establecen relaciones interpersonales y grupales y que actúan como formadoras de identidades que refuerzan el sentido de pertenencia y de diferenciación de otros universos culturales. En este sentido, nos parece relevante recorrer no sólo aquellos espacios de sociabilidad formal -más ligados a instancias institucionales- como los de sociabilidad informal -más ligados a la sociabilidad privada- al modo de las categorías propuestas por Agulhon, ${ }^{31}$

Por último, pensamos que una perspectiva como la que adoptamos se acerca más a un análisis que sin negar la ligazón existente entre el catolicismo tercermundista y Montoneros considera que la matriz católica que se despliega más notoriamente en sus orígenes -aunque sólo en algunos de sus miembros fundadores- no alcanza para explicar su posterior desarrollo ni la adopción de una estrategia militarista, autoritaria y mesiánica.

Reafirmamos la idea de que existía un amplio espectro de posibilidades de participación y militancia para los jóvenes católicos y los jóvenes, en general, y ningún camino parecía conducir de manera directa a la acción insurreccional. En todo caso, por el lado del catolicismo, habría que intentar explicar ¿por qué los planteos más acordes a la línea renovadora post-conciliar propiamente dicha quedaron atrapados y silenciados frente a la "guerra" entre neo-integristas y tercermundistas?

La explicación de la violencia insureccional en los años '70 y su brutal respuesta represiva estatal y paraestatal, no puede reducirse al influjo del "mito" de la nación católica cuya tradición autoritaria es clara. De actores ignorados, los católicos recientemente descubiertos por la historiografía de la historia reciente se están convirtiendo en casi los principales artífices de las prácticas insurgentes y autoritarias de las agrupaciones armadas. La operación historiográfica obedece pues en este caso más a una tendencia en boga que aunque comprensible en parte, corre el riesgo de cristalizarse con propensión al desbalance a la hora de interpretar con mayor rigor los alcances del filón católico de la violencia setentista. Para comprender ¿quién destapó la "Caja de Pandora"? de la tragedia argentina de aquellos años, los historiadores

\footnotetext{
${ }^{31}$ Aguhlon, Maurice. (1977). Le cercle dans la France bourgeoise, 1810-1848: étude d'une mutation de sociabilité, Paris: Armand Colin.
} 
necesitamos animarnos a un ejercicio sin duda más incómodo que es recomponer un arco temporal que se extienda más atrás en el siglo XX. En él debería volver a revisarse el peso de otras tradiciones intelectuales y el protagonismo de otros actores políticos y sociales. En síntesis, una vía más articulada y compleja para evaluar los avatares de una sociedad donde la democracia fue cuestionada casi desde su puesta en vigencia en el sistema político y en relación con el tipo de representaciones y prácticas que la sociedad se fue forjando en torno a ella. 